\title{
Binomial effects of high isostatic pressure and time on the microbiological, sensory characteristics and lipid composition stability of vacuum packed dry fermented sausages “chouriço”
}

\author{
António Alfaia ${ }^{\mathrm{a}, 1}$, Cristina M. Alfaia ${ }^{\mathrm{b}, 1}$, Luís Patarata ${ }^{\mathrm{c}}$, Maria J. Fernandes ${ }^{\mathrm{b}}$, Maria H. Fernandes ${ }^{\mathrm{b}}$, Miguel Elias ${ }^{\mathrm{d}}$, \\ Maria H. Ribeiro ${ }^{a}$, Maria J. Fraqueza ${ }^{\text {b,* }}$ \\ a iMed-FFUL, Faculdade de Farmácia, Av. Professor Gama Pinto, 1649-003 Lisboa, Portugal \\ b CIISA, Faculdade de Medicina Veterinária, Universidade de Lisboa, Av. da Universidade Técnica, Pólo Universitário do Alto da Ajuda, $1300-477$ Lisboa, Portugal \\ c CECAV, Universidade de Trás-os-Montes e Alto Douro, 5001-801 Vila Real, Portugal \\ d ICAAM, Universidade de Évora, Pólo da Mitra, Ap. 94, 7002-554 Évora, Portugal
}

\section{A R T I C L E I N F O}

\section{Article history:}

Received 13 August 2015

Received in revised form 23 September 2015

Accepted 25 September 2015

Available online 8 October 2015

\section{Keywords:}

High pressure processing

Dry fermented sausage

Spoilage

Fatty acid composition

Lipid oxidation

Quality

\begin{abstract}
A B S T R A C T
The effect of high pressure processing (HPP), at different combinations of pressure and time, on dry fermented sausages (DFS) was evaluated by chemical, microbiological and sensory analyses. Lipid composition and stability were also assessed. HPP ( $>400 \mathrm{MPa}$ and longer than $154 \mathrm{~s}$ ) produced a reduction in spoilage microbiota, without negative effect on fermentative microbiota, that will be able to continue their role. Total fatty acids and lipid stability were not affected. Only a small effect on fatty acid (FA) composition was observed. Nutritional value of the lipid fraction was only affected by the ratio $n-6 / n-3$ FA. Treatments at $400 \mathrm{MPa}$ for $154 \mathrm{~s}$ or $960 \mathrm{~s}$ resulted in DFS being detected as different from control by sensory analysis. Those differences did not depreciate the product; on the contrary it seems to improve the bright aspect of the whole sausage, the cohesion and firmness and the correctly dried aspect of slices.

Industrial relevance: Dry fermented meat sausages are very popular ready-to-eat meat based products. This study assesses the effects of HPP on this much appreciated traditional products. The results showed that HPP can be successfully applied to these Mediterranean fermented products without losses of sensory and nutritional characteristics. The modelling and optimization of the HPP process applied on dry fermented sausages demonstrated in this study are an advantage to industry efficiency. The utilisation of HPP by the industry can significantly increase dry fermented meat sausage shelf life and safety, providing it an opportunity to reach the global market.
\end{abstract}

(c) 2015 Elsevier Ltd. All rights reserved.

\section{Introduction}

Traditional meat sausages in the Mediterranean countries are characterised by a great diversity of products that are appreciated by the consumers. The particular sensory characteristics of these products are related to the fermentative microbiota and to the process of drying and/or smoking. The manufacturing process of dry fermented sausages (DFS) does not have any step that ensures the elimination of pathogens. Thus, its microbial safety relies on fermentation and drying steps giving the final stability characteristics to the product, however, any eventual failure in the process might result in DFS potentially hazardous to consumer (Fraqueza \& Barreto, 2015).

The increasing demand of consumers for traditional meat products leads to the application of new processing technologies by which synergic

\footnotetext{
* Corresponding author.

E-mail address: mjoaofraqueza@fmv.ulisboa.pt (M.J. Fraqueza).

1 Authors who contributed equally.
}

effects can assure safety, improve shelf-life and quality of traditional meat products. Among the so-called emergent technologies, high pressure processing (HPP), using high isostatic pressure, seems to be a valuable alternative technology in food processing. One important advantage of HPP technology is the significant levels of microbial inactivation in meat products while minimal effects on the sensory and nutritional quality are detected (Garriga, Grèbol, Aymerich, Monfort, \& Hugas, 2004; Rendueles, Omer, Alvseike, Alonso-Calleja, Capita, et al., 2011). High pressure processing is accepted as a safe and consumer friendly technology due to its capacity to destroy microorganisms, regardless of the geometry of the product and without the drawback of the heat damage modifications (Rastogi, Raghavarao, Balasubramaniam, Niranjan, \& Knorr, 2007; Zhang \& Mittal, 2008). However, the effectiveness of high pressure on meat food constituents depends on numerous factors including initial microbiota, $\mathrm{pH}$ and ionic strength (McArdle, Marcos, Kerry, \& Mullen, 2010). Therefore, the effect of HPP treatment on the quality of meat products warrants further insights. The present study was carried out to evaluate the effect of HPP on the microbiological, lipid composition and oxidative stability and on sensory characteristics 
of a DFS chouriço processed at different pressures (200 to $600 \mathrm{MPa}$ ) and times (153 s to $1800 \mathrm{~s}$ ).

\section{Material and methods}

\subsection{Dry fermented sausage production}

Dry fermented sausage used in the experiment was chouriço. It was prepared by grinding $(25 \mathrm{~mm})$ pork meat from commercial crossbred (Iberian $\times$ Duroc) containing 30\% fat and mixing with white wine (8\%), salt (2.5\%), red pepper paste (Capsicum annuum L., 2.5\%), garlic paste (Allium sativum L., $0.8 \%$ ), $\mathrm{NaNO}_{3}(0.02 \%), \mathrm{KNO}_{3}(0.008 \%), \mathrm{KNO}_{2}$ $(0.007 \%)$, disodium diphosphate $(0.03 \%)$, pentasodium triphosphate $(0.03 \%)$, ascorbic acid $(0.03 \%)$ and sodium ascorbate $(0.02 \%)$. The mixture was kept at $5{ }^{\circ} \mathrm{C}$ during $2 \mathrm{~d}$ and stuffed into $36-38 \mathrm{~mm}$ diameter natural pork casings in sausages of $180-200 \mathrm{~g}$ with horseshoe shape. Chouriço samples were smoked at $18-24{ }^{\circ} \mathrm{C}$ and a relative humidity of 30-60\% during $48 \mathrm{~h}$ with oak wood (Quercus ilex L.) smoke followed by a curing/drying period of $25 \mathrm{~d}$ at $9{ }^{\circ} \mathrm{C}$. Sausages were vacuum packed (TURBOVAC, 700 STE-XL, The Netherlands) in polyamide and polyethylene (PA/PE) bags $\left(\mathrm{O}_{2}\right.$ permeability: $75 \mathrm{~cm}^{3} / \mathrm{m}^{2} /$ day; $\mathrm{CO}_{2}$ permeability: $415 \mathrm{~cm}^{3} / \mathrm{m}^{2} /$ day and $85 \% \mathrm{RH}$; water-vapour permeability: $<10 \mathrm{~g} / \mathrm{m}^{2} /$ day at $23{ }^{\circ} \mathrm{C}$; Alempack, Elvas, Portugal) and stored at $3 \pm 2{ }^{\circ} \mathrm{C}$ until analysis.

\subsection{Experimental design}

The binomial effect of time and pressure during HPP was studied using Response Surface Methodology (RSM) (Giovanni, 1987), which is a technique for the modelling and optimization of multiple variables in order to predict the best performance conditions with a minimum number of experiments. It consists of a group of mathematical and statistical procedures that can be used to study relationships between one or more responses and a number of independent variables and to model the overall process. The study of these effects between variables is difficult to detect by a traditional experimental design where one variable is changed at a time. The coefficients of the mathematical model (usually a polynomial equation) representing the variations of the experimental response of interest may be evaluated with high precision. Additionally, RSM has the advantage of being less expensive and time consuming than the classical methods. In this work, RSM was used to compare the combined effects of time and pressure of analysed parameters of the samples submitted to HPP (Marqués, Vila-Real, Alfaia, \& Ribeiro, 2007, Ribeiro, Silveira, Ebert, \& Ferreira-Dias, 2003).

The experiments were carried out with a central composite rotatable design (CCRD) (Vuataz, 1986) as a function of time and pressure (Table 1). With CCRD, five levels for each factor were used, which allowed a fit of first or second-order polynomials to the experimental data points. Eleven experiments were carried out in CCRD: four factorial points [coded levels as $(+1)$ and $(-1)$ ]; four star points [coded as $(+\sqrt{2})$ and $(-\sqrt{2})]$ and three center points, coded as 0 (Table 2$)$, using the software "StatisticaTM", version 5 (Statsoft, USA).

Vacuum packaged samples were submitted to isostatic pressure (high pressure food processor, N.C. Hyperbaric, Wave 6000/135) between 200 and $600 \mathrm{MPa}$ at controlled temperature $\left(10^{\circ} \mathrm{C}\right)$ and from 154 to $1800 \mathrm{~s}$ ( $n=3$ for each treatment), according to the experimental

Table 1

Coded and decoded levels of the experimental factors used in central composite rotatable design.

\begin{tabular}{llc}
\hline CCRD & Pressure $(\mathrm{MPa})$ & Time $(\mathrm{s})$ \\
\hline$-\sqrt{2}$ & 202 & 154 \\
-1 & 260 & 390 \\
0 & 400 & 960 \\
+1 & 540 & 1530 \\
$+\sqrt{2}$ & 600 & 1800 \\
\hline
\end{tabular}

\section{Table 2}

Experimental data obtained for the optimization of pressure and time on chouriço processing.

\begin{tabular}{llr}
\hline No & Pressure/Mpa & Time/s \\
\hline 1 & 202 & 960 \\
2 & 260 & 390 \\
3 & 260 & 1530 \\
4 & 400 & 154 \\
5 & 400 & 960 \\
6 & 400 & 960 \\
7 & 400 & 960 \\
8 & 400 & 1800 \\
9 & 540 & 390 \\
10 & 540 & 1530 \\
11 & 600 & 960 \\
\hline
\end{tabular}

design (Table 2) the rates of compression and decompression were controlled automatically. After treatment, samples were transported to laboratory under refrigeration and stored at $3 \pm 2{ }^{\circ} \mathrm{C}$. Microbiological, lipid composition and sensory analyses were performed in the first $5 \mathrm{~d}$ after HPP. Oxidation stability assayed through TBARS was performed after $30 \mathrm{~d}$ of storage.

\section{3. $\mathrm{pH}$ and water activity determination.}

The $\mathrm{pH}$ was measured using a pH metre (HI 9025; electrode FC 230B) with a glass pH probe (FC 230B, Hanna Instruments, USA) by direct insertion into each sample. Three measurements were made in each sample. Water activity $\left(\mathrm{a}_{\mathrm{w}}\right)$ was measured using a Rotronic Hygrometer station (Rotronic Hygroskop DT, Ettlingen, Germany) at $23^{\circ} \mathrm{C}$.

\subsection{Microbial analysis}

The microbial counts carried out were Enterobacteriaceae, Pseudomonas spp., Staphylococcus cocci Gram-positive catalase-positive (GPCP), lactic acid bacteria (LAB), Enterococcus spp., fungi and Listeria monocytogenes, according to the procedures described elsewhere (Talon et al., 2007). Escherichia coli counts was determined in PTX BCIG Tergitol Agar (PTX, Scharlau, Barcelona, Spain), $44.5^{\circ} \mathrm{C}, 24 \mathrm{~h}$ (ISO 16649-2).

\subsection{Lipid extraction and fatty acid composition}

Lipid extraction was performed according to the method of Folch and Stanley modified by Boselli, Velazco, Caboni, and Lercker (2001). The fat content was measured gravimetrically, in duplicate, by weighting the residue obtained after solvent evaporation.

The fatty acid (FA) composition of DFS was determined as their fatty acid methyl ester (FAME) derivatives. Briefly, FAMEs were directly prepared from meat sausages by a transesterification procedure with $\mathrm{KOH}(10 \mathrm{M})$ in methanol followed by the addition of $\mathrm{H}_{2} \mathrm{SO}_{4}(24 \mathrm{M})$ according to O'Fallon, Busboom, Nelson, and Gaskins (2007). Then, FAMEs were analysed by fast gas-liquid chromatography using a gas chromatograph HP7890A (Hewlett-Packard), equipped with a flame ionisation detector (GC-FID) and a Supelcowax ${ }^{\mathrm{TM}} 10$ fused capillary column (10 $\mathrm{m} \times 0.10 \mathrm{~mm}$ i.d., $0.10 \mu \mathrm{m}$ film thickness; Supelco, Bellefonte, CA). Initial oven temperature of $100{ }^{\circ} \mathrm{C}$ was increased to $250{ }^{\circ} \mathrm{C}$ at a rate of $70{ }^{\circ} \mathrm{C} / \mathrm{min}$, then increased to $260{ }^{\circ} \mathrm{C}$ at a rate of $50{ }^{\circ} \mathrm{C} / \mathrm{min}$ and maintained for $5 \mathrm{~min}$. Helium was used as carrier gas at a flow rate of $1 \mathrm{~mL} / \mathrm{min}$ and $1 \mu \mathrm{L}$ of sample was injected. The injector and detector temperatures were $240{ }^{\circ} \mathrm{C}$ and $280{ }^{\circ} \mathrm{C}$, respectively. Identification of FAME was achieved by comparison of the FAME retention times with those of authentic standards (FAME mix 37 components from Supelco Inc., Bellefont, PA, USA). The quantification of total FAMEs was done using non-adecanoic acid (19:0) as the internal standard and the conversion of relative peak areas into weight percentages. FAs were expressed as mg/100 $\mathrm{g}$ of dry fermented sausages. 


\subsection{Lipid oxidation}

Lipid oxidation in DFS was evaluated by measuring secondary lipid oxidation products through thiobarbituric acid-reactive substances (TBARS) as previously described by Grau, Guardiola, Boatella, and Codonyl (2000). TBARS were expressed as mg of MDA/kg of sausage.

\subsection{Sensorial evaluation}

A triangle test was made according to ISO 4120 (2004). Sessions occurred in a controlled sensory analysis laboratory with trained panellists. Each panellist performed 9 triangle tests, corresponding to the 9 pressureholding time combinations. Each test was composed by two slices for each of the triangle points, anonymously coded.

In order to get a deeper insight on the modifications eventually introduced by the HPP, a qualitative approach was conducted with two focus groups. One composed by seven participants with previous experience on sensory analysis of DFS ( 3 males, 4 females; 25 to 58 years) and other composed by six participants with no experience on sensory analysis ( 2 males, 4 females; 28 to 62 years). The moderator facilitated the discussion according to previously planned guidelines (Table 3) (Chung, Hong, Kim, Cho, \& Moskowitz, 2011). Samples were presented in the discussion by the experimental design order. The sessions were audio recorded. After transcription of the audio files, the content was analysed for detection of sensory trends for each HPP treated sausage. In both approaches spring water and unsalted bread were provided.

\subsection{Statistical analysis}

Both linear and quadratic effects of the two variables under study, as well as their interactions, on $\mathrm{pH}$ and $\mathrm{a}_{\mathrm{w}}$, microbiological counts, and fatty acids were calculated. A surface, described by a second-order polynomial equation, was fitted to each set of experimental data points.

Results were expressed as mean \pm standard error (SE) and checked, also, for normality and variance homogeneity using the Statistical Analysis Systems (SAS) software package, version 9.3 (SAS Institute, Cary, NC, USA). The model considered the treatment as the single effect. Total fatty acid content was retained as a covariate. The GLM procedure was used to perform analysis of variance and differences between treatments were calculated using the Tukey's post hoc test at $P<0.05$. For triangle sensorial analysis, the data were analysed by comparisons of the number of correct answers - the panellist considered different the

Table 3

Discussion guideline used in the focus group on the sensory attributes of HPP treated chouriço.

\footnotetext{
1.1 Introduction and guidelines: Moderator presentation; Information about the audio recording of the session; general information about the research objectives and the product to be tested. One person talk at a time; ensure the proximity of the micro; free to do not participate; respect the others point of view (5 min);

1.2 Warm up: Age, habits of chouriço and other dry cured meat products consumption; what kind of products are consumed at home; who purchases these products at home (self, spouse; other) (10 min).

1.3 Probing questions

1.3.1 Packaged chouriço (15 min)

a. Describe the characteristics of the packaged chouriço;

b. From the former characteristics which are considered negative or positive attributes;

c. What is your possible willingness to buy this product;

1.3.2. Unpackaged whole chouriço (repeat 1.3.1.a and 1.3.1.b) (10 min)

1.3.2 Sliced chouriço (20 min)

a. Describe the chouriço characteristics for the dimension aspect, smell, taste,

flavour and texture;

b. Point out the negative and positive attributes;

1.3.4. From all the aspects discussed, which are those you consider more important

in the negative and positive sense ( $5 \mathrm{~min}$ )

1.4 Conclusion: Clarification of eventual doubts and acknowledgments (5 min)
}

sample without HPP treatment from the set of three - to the table of binomial law.

\section{Results and discussion}

\subsection{Effect of HPP on $\mathrm{pH}, \mathrm{a}_{w}$ and microbiological parameters}

Table 4 presents the HPP effect on $\mathrm{pH}, \mathrm{a}_{\mathrm{w}}$ and microbiological parameters of traditional DFS. The $\mathrm{pH}$ values for control samples were around 4.84 and between 4.88 to 5.30 for HPP samples. High pressure processing was shown to induce a significant increase in $\mathrm{pH}$ when some HPP conditions were applied $(P<0.001)$ compared with untreated samples. Considering the effects summarised in Table 5 , the linear and quadratic terms of pressure were highly significant $(P<0.01$ and $P<0.05$, respectively). No significant effect of time or interaction between the variables tested were observed $(P>0.05)$.

The multiple regression analysis performed to fit the second order polynomial equations to the experimental data can be described by response surfaces (Fig. 1), which show the relationship between independent and dependent variables in three-dimensional representation.

The trend of $\mathrm{pH}$ increase in pressurised meat products was also reported in raw sausage batter, fresh chicken breast fillets and raw poultry sausages (Lerasle, Federighi, Simonin, Anthoine \& Rezé et al., 2014; Rodríguez-Calleja, Cruz-Romero, Sullivan, García-López, \& Kerry, 2012). This pattern has been attributed to the redistribution of ions that is facilitated by the increased ionisation that occurs at elevated pressures. It might also be due to the release of imidazolium groups by histidine by the unfolding of actomyosin during pressurisation (MacFarlane, McKenzie, \& Turner, 1980). In the present work, pressurising at 400 and $600 \mathrm{MPa}$ resulted in the highest $(P<0.001)$ $\mathrm{pH}$ values when compared with samples pressurised at 200-260 MPa, independent of the holding time (Table 4). McArdle et al. (2010) also observed no increase on $\mathrm{pH}$ values of beef treated at $200 \mathrm{MPa}$, while increasing pressure induced an increase of $\mathrm{pH}$ values of beef.

The $a_{w}$ value presented by the control samples was 0.94 (Table 4) while in DFS submitted to HPP a significant, still slightly, $\mathrm{a}_{\mathrm{w}}$ decrease $(P<0.01)$ was noticed. These sausages presented a combination of $\mathrm{pH}$ and $\mathrm{a}_{\mathrm{w}}$ that allow classifying them as stable, however, those suffering HPP despite the increase of $\mathrm{pH}$ induced by HPP treatment are still protected by low $\mathrm{a}_{\mathrm{w}}$ hurdle (Leistner, Rodel, \& Krispien, 1981).

HPP processing destroys vegetative microbial cells and inactivates certain enzymes (Simpson \& Gilmour, 1997). The effectiveness of the treatment depends primarily on the pressure applied and on the holding time. It is of note the reduction effect of HPP on Gram negative bacteria group, such as Enterobacteriaceae and Pseudomonas spp., present on DFS (Table 4). The Enterobacteriaceae count of control DFS was $4.49 \pm 0.15 \log (\mathrm{CFU} / \mathrm{g})$. The lower pressure treatment 202-260 MPa, independent of the holding time, induced an approximately 3 log reduction. When the pressure was increased over $400 \mathrm{MPa}$ both Enterobacteriaceae and Pseudomonas spp. were below the detection limit. This lethal effect of HPP was also observed on fungi counts particularly when the treatment was applied for a longer time than $154 \mathrm{~s}$ for $400 \mathrm{MPa}$ or beyond. The fermentative group of the LAB in DFS was not affected by pressure treatments lower than $400 \mathrm{MPa}$, while the increase of pressure above that value resulted in a higher lethality dependent on the holding time. The GPCP and Enterococcus spp. apparently were more sensitive than the LAB to the HPP with 1-2 log reductions. E. coli and $L$. monocytogenes were below the detection limit in all the experimental conditions.

The Gram positive microbiota evaluated on the present study was less affected by HPP treatments than the Gram negative. The different chemical compositions and structural properties of the cell membrane in Gram-positive and Gram-negative microorganisms results in differences in resistance to HPP (Ikeuchi, 2011). The first are generally more resistant than the second ones (Shigehisa, Ohmori, Saito, Taji, \& Hayashi, 1991). Apparently, the double-layered phospholipids which 


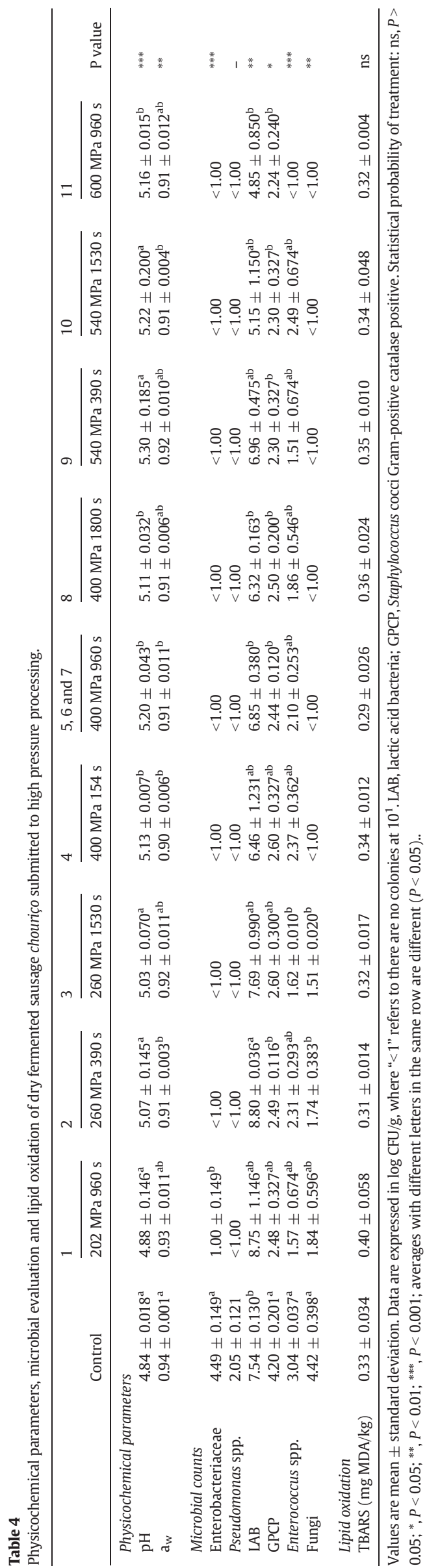

are present in the lipid membranes are packed tightly during the compression phase, promoting the transition towards a gel state (Hazel \& Williams, 1990), and during decompression the dual layer structure is lost, with pore formation and cytoplasmic material leaking (Hoover, Dishart, \& Hermes, 1989; Shimada et al., 1993). The membrane must maintain the fluid state to maintain its function and properties, and fluidity is mainly determined by composition and percentages of unsaturated fatty acids.

The effects of pressure $(P)$, time $(t)$ and interaction $(P \times t)$ on microbial counts of LAB, GPCP and Enterococcus spp. as well on pH are presented in Table 5. The experimental results showed that Enterococcus spp. count reduction was not statistically affected by P and t individually and interactively. However, negative effects of the factors $P$ or $t$ or their interaction $(\mathrm{P} \times \mathrm{t})$ are disclosed for LAB and GPCP, which indicates that the microbial counts decreased with the increase in these factors. Linear term of pressure was highly significant for GPCP $(P<0.05)$ and LAB $(P<0.01)$. A negative interaction between the variables tested $(\mathrm{P} \times \mathrm{t})$ confirms that higher count reduction was obtained at higher pressures and higher times.

For most forms of vegetative bacteria, significant reductions, usually higher than $4 \log \mathrm{CFU} / \mathrm{g}$, in the population are achieved when 400 to $600 \mathrm{MPa}$ at ambient temperature are used (Rendueles et al., 2011). All these facts seem to be beneficial on fermented sausages since under the effect interaction $(\mathrm{P} \times \mathrm{t})$ it will be possible to have a reduction of the spoilage microorganisms while the technological bacteria will not be significantly affected or only slightly affected and being able to continue their role regarding the development of DFS sensorial characteristics and protection against microbial hazards. These results could lead us to consider another moment for the HPP treatment application such as the step of DFS post stuffing since the spoilage microbiota could be reduced and the fermentation will proceed till the final product.

\subsection{Effect of HPP on fatty acid composition}

Total FAs (mg/g sausage) and composition ( $\mathrm{g} / 100 \mathrm{~g}$ of total FAs) of traditional DFS subjected to HPP are shown in Table 6. The total FA contents varied from 292 to $406 \mathrm{mg} / \mathrm{g}$ of product, however, those were not affected $(P>0.05)$ by HPP. In addition, no significant changes $(P>0.05)$ were observed for fat content (data not shown).

The detailed FA composition of DFS is summarised in Table 6. The composition of FA is one of the most important components that can change during processing, affecting sensory proprieties and nutritional value of food (Wood et al., 2008). The major FA detected were oleic (18:1c9, 43.7-45.7\%), palmitic (16:0, 23.0-24.2\%), stearic (18:0, 12.5$13.4 \%)$ and linoleic $(18: 2 n-6,6.40-7.43 \%)$ acids. The effect of HPP treatment $(P<0.05)$ was detected only in five of the $30 \mathrm{FA}$ analysed. The FA influenced by HPP were 14:1c9 $(P<0.001)$ followed by some $n-3$ PUFA (polyunsaturated fatty acids) $(22: 6 n-3,22: 5 n-3$, $20: 3 n-3)$ and $22: 1 n-9$. A possible hypothesis could be that $n-6$ PUFA are structural lipids that are less susceptible to alterations by HPP. No changes $(P>0.05)$ in the partial sums of FA were observed

Table 5

Effects and respective significance levels of pressure and time on lactic acid bacteria (LAB), Staphylococcus cocci Gram-positive catalase-positive (GPCP) and Enterococcus spp. counts and $\mathrm{pH}$.

\begin{tabular}{lrrrr}
\hline Variables & \multicolumn{1}{l}{ LAB } & GPCP & Enterococcus & \multicolumn{1}{l}{$\mathrm{pH}$} \\
\hline Pressure (linear term) & $-2.471^{* *}$ & $-0.206^{*}$ & -0.531 & $0.204^{* *}$ \\
Pressure (quadratic term) & 0.225 & -0.094 & -1.054 & $-0.139^{*}$ \\
Time (linear term) & -0.764 & -0.011 & -0.120 & -0.036 \\
Time (quadratic term) & -0.160 & 0.089 & 0.243 & -0.038 \\
$\mathrm{P} \times \mathrm{t}$ & -0.350 & -0.055 & 0.835 & -0.020 \\
\hline
\end{tabular}

$P$, pressure; $t$, time.

* $P<0.05$.

** $P<0.01$. 

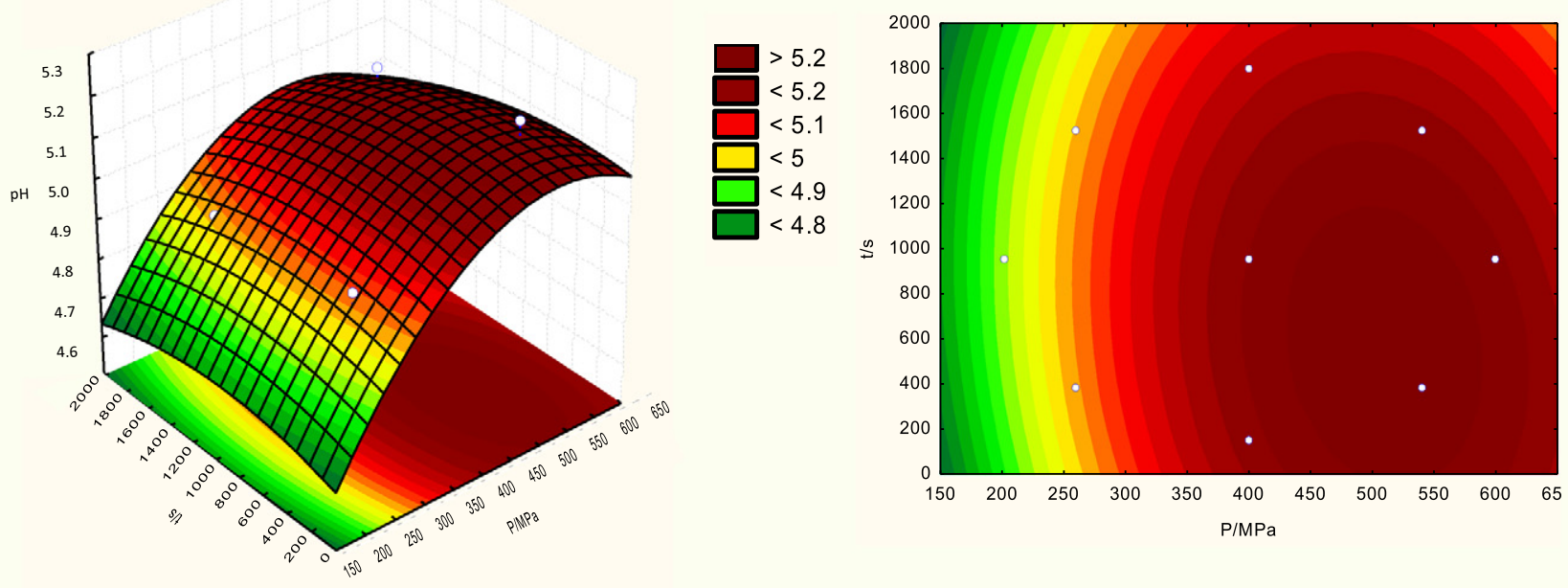

Fig. 1. Response surface and respective contour plot fitted to the experimental data points, corresponding to $\mathrm{pH}$, as a function of time (s) and pressure (MPa).

for DFS, reflecting the patterns described above for individual FA. The ratios of PUFA/SFA and $n-6 / n-3$, which are indexes widely used to evaluate the nutritional value of fat for human consumption, are also presented in Table 6. In all samples analysed HPP did not affect the PUFA/SFA, however, the $n-6 / n-3$ was significantly $(P<0.05)$ influenced by HPP, especially by treatments 5, 6, 7 (400 MPa-960 s) and treatment 8 ( $400 \mathrm{MPa}-1800 \mathrm{~s}$ ). The nutritional recommendations are that the PUFA/SFA ratio should be above 0.45 (Wood et al., 2008) and, within the PUFA, the $n-6 / n-3$ ratio should not exceed 4.0 (Department of Health, 1994; Simopoulos, 2008). The PUFA/SFA ratios in this study (0.20-0.22) were below the values for the human diet. In contrast to the PUFA/SFA index, the values of the $n-6 / n-3$ ratios were higher (11.0-14.6) to the recommended guideline for the human diet, which result from the high amounts of $n-6$ PUFA and the lower contents of $n-3$ fatty acids.

\subsection{Effect of HPP on lipid oxidation}

The TBAR values are a measure of the degradation products of lipid hydroperoxides formed during the oxidation process of FA (Guillén \& Ruiz, 2004). The HPP treatment had no significant effect $(P=0.419)$ in any experimental condition (Table 4). Lipid oxidation in DFS has a dual role. On one hand it is a key process to the development of the characteristic aroma of DFS (Ordoñez, Hierro, Bruna, \& de la Hoz, 1999), but if it is excessive leading to the occurrence of rancid aroma it is one of the primary causes of sensory rejection (Morrissey, Sheehy, Galvin, Kerry, \& Buckley, 1998). Literature data on the effect of HPP treatment on lipid oxidation development in meat products are somehow controversial. It has been suggested that HPP triggers lipid oxidation by two mechanisms, increased accessibility for iron from hemoproteins and membrane disruption (Bajovic, Bolumar, \& Heinz, 2012). In DFS prepared with nitrite the availability of iron for participation on oxidation is more limited than in other meat products and fresh meat (Clariana et al., 2011). In the present study the similar extension of oxidation observed after HPP treatment might also be associated to the use of vacuum packaging of DFS. It is known that oxidation do not increase immediately after the pressure treatment, but during subsequent storage of the products (Beltran, Pla, Yuste, \& Mor-Mur, 2004; Orlien, Hansen, \& Skibsted, 2000), that might have contributed to the low levels of TBARS observed in the present work. However, Tuboly, Lebovics, Gaál, Mészáros, and Farkas (2003) on turkey meat observed an increase in oxidation just after the pressure treatment.

\subsection{Effect of HPP on sensorial characteristics}

The results of a triangle test between control DFS and those processed by HPP are presented in Table 7 . The samples under conditions $400 \mathrm{MPa}$ and $540 \mathrm{MPa}-390 \mathrm{~s}$ were different $(P<0.05)$ from the control. The lower and the higher HPP treatments did not produce modifications detectable by the panellists. To have a better understanding of the modifications eventually introduced by the HPP a focus group approach was conducted with the samples still packaged, whole without the package and sliced. The main findings are summarised in Table 7. Sensory attributes of the packaged DFS might be grouped in two classes: (1) characteristics related to the formulation and technology - amount of fat, red pepper paste; size of meat and fat pieces and (2) those putatively related to the HPP, once they were variable among samples with different treatments - amount and type of exudate; brightness of the surface; and moisten/dull aspect. The majority of the samples analysed by the focus group had an exudate in the package. It was observed that there is a tendency to have brownish exudates in samples treated with lower pressure-time and greyish white, milky, exudates in samples submitted to higher pressure and/or time (from $400 \mathrm{MPa}-1800 \mathrm{~s}$ to $540 \mathrm{MPa}-1530 \mathrm{~s}$ ). Associated with the presence of exudates, participants also refer that the surface was dull, not bright as expected for vacuum packaged DFS, and that the samples looked insufficiently dried. The presence of greyish white exudate was unanimously considered not appellative and the main criteria for not willing to purchase the product. Nonetheless the tendency to have increasing amounts of unpleasant exudates with the HPP conditions increase was observed, but that relationship cannot be clearly established. Once with some pressure time combinations, the final product resulted well, as observed for $400 \mathrm{MPa}$ during $154 \mathrm{~s}$ or $960 \mathrm{~s}$, characterised by the absence of exudate and a brighter surface, and consensually willed to purchase, but with an increase of treatment time to $1800 \mathrm{~s}$ at the same pressure, it became unacceptable due to the presence of high amounts of exudates. With the highest pressure tested (600 MPa-960 s) the product presented only low amounts of a translucent exudate and have a dry and bright surface. The presence of exudate results from the modification of the water holding capacity (WHC) of the meat proteins that in turn, can be influenced by several phenomena, namely the physical compression of the muscular structure, the pressure induced denaturation of proteins, modification of proteolysis patterns mainly associated membrane damages and consequent $\mathrm{Ca}^{2+}$ and $\mathrm{Mg}^{2+}$ release (Sun \& Holley, 2010). The relationship between HPP and WHC is variable in different research reported in the literature. Several studies concluded that the use of HPP 
Total fatty acid (FA) content (mg/g) and composition (\% of total fatty acids) of dry fermented sausage chouriço submitted to HHP.

\begin{tabular}{|c|c|c|c|c|c|c|c|c|c|c|c|}
\hline & Control & 1 & 2 & 3 & 4 & 5,6 and 7 & 8 & 9 & 10 & 11 & \\
\hline & & $202 \mathrm{MPa} 960 \mathrm{~s}$ & $260 \mathrm{MPa} 390 \mathrm{~s}$ & $260 \mathrm{MPa} 1350 \mathrm{~s}$ & $400 \mathrm{MPa} 154 \mathrm{~s}$ & $400 \mathrm{MPa} 960 \mathrm{~s}$ & $400 \mathrm{MPa} 1800 \mathrm{~s}$ & $540 \mathrm{MPa} 390 \mathrm{~s}$ & $540 \mathrm{MPa} 1530 \mathrm{~s}$ & $600 \mathrm{MPa} 960 \mathrm{~s}$ & $P$ value \\
\hline Total FA & $304 \pm 27.5$ & $332 \pm 47.6$ & $336 \pm 27.5$ & $289 \pm 33.7$ & $392 \pm 27.5$ & $337 \pm 15.9$ & $406 \pm 27.5$ & $302 \pm 33.7$ & $292 \pm 33.7$ & $323 \pm 33.7$ & ns \\
\hline \multicolumn{12}{|c|}{ Fatty acid composition } \\
\hline $10: 0$ & $0.06 \pm 0.003$ & $0.06 \pm 0.006$ & $0.06 \pm 0.003$ & $0.06 \pm 0.004$ & $0.07 \pm 0.004$ & $0.07 \pm 0.004$ & $0.06 \pm 0.004$ & $0.06 \pm 0.004$ & $0.06 \pm 0.004$ & $0.06 \pm 0.004$ & ns \\
\hline $12: 0$ & $0.07 \pm 0.003$ & $0.06 \pm 0.005$ & $0.07 \pm 0.003$ & $0.07 \pm 0.004$ & $0.08 \pm 0.003$ & $0.08 \pm 0.002$ & $0.07 \pm 0.003$ & $0.07 \pm 0.003$ & $0.07 \pm 0.004$ & $0.07 \pm 0.003$ & ns \\
\hline $14: 0$ & $1.33 \pm 0.018$ & $1.29 \pm 0.030$ & $1.25 \pm 0.018$ & $1.28 \pm 0.023$ & $1.33 \pm 0.019$ & $1.31 \pm 0.010$ & $1.33 \pm 0.020$ & $1.31 \pm 0.022$ & $1.33 \pm 0.022$ & $1.30 \pm 0.022$ & ns \\
\hline $14: 1 c 9$ & $0.03 \pm 0.002^{\mathrm{a}}$ & $0.02 \pm 0.003^{b}$ & $0.02 \pm 0.002^{\mathrm{b}}$ & $0.02 \pm 0.002^{\mathrm{b}}$ & $0.02 \pm 0.002^{\mathrm{b}}$ & $0.02 \pm 0.001^{\mathrm{b}}$ & $0.02 \pm 0.002^{\mathrm{ab}}$ & $0.02 \pm 0.002^{\mathrm{b}}$ & $0.02 \pm 0.002^{\mathrm{b}}$ & $0.02 \pm 0.002^{\mathrm{b}}$ & $* * *$ \\
\hline $15: 0$ & $0.05 \pm 0.003$ & $0.04 \pm 0.005$ & $0.04 \pm 0.003$ & $0.04 \pm 0.004$ & $0.04 \pm 0.003$ & $0.05 \pm 0.002$ & $0.05 \pm 0.004$ & $0.05 \pm 0.004$ & $0.05 \pm 0.004$ & $0.04 \pm 0.004$ & ns \\
\hline DMA-16:0 & $0.12 \pm 0.009$ & $0.08 \pm 0.016$ & $0.08 \pm 0.009$ & $0.10 \pm 0.012$ & $0.08 \pm 0.010$ & $0.09 \pm 0.005$ & $0.10 \pm 0.011$ & $0.13 \pm 0.012$ & $0.10 \pm 0.012$ & $0.09 \pm 0.011$ & ns \\
\hline $16: 0$ & $23.8 \pm 0.353$ & $24.2 \pm 0.592$ & $23.9 \pm 0.342$ & $23.2 \pm 0.439$ & $23.1 \pm 0.376$ & $23.6 \pm 0.197$ & $23.0 \pm 0.393$ & $23.9 \pm 0.430$ & $23.7 \pm 0.436$ & $23.4 \pm 0.402$ & ns \\
\hline $16: 1 c 9$ & $2.62 \pm 0.050$ & $2.43 \pm 0.083$ & $2.47 \pm 0.048$ & $2.41 \pm 0.062$ & $2.54 \pm 0.053$ & $2.54 \pm 0.028$ & $2.51 \pm 0055$ & $2.51 \pm 0060$ & $2.52 \pm 0.061$ & $2.51 \pm 0.059$ & ns \\
\hline $17: 0$ & $0.27 \pm 0.009$ & $0.26 \pm 0.015$ & $0.28 \pm 0.008$ & $0.27 \pm 0.011$ & $0.26 \pm 0.009$ & $0.27 \pm 0.005$ & $0.28 \pm 0.010$ & $0.29 \pm 0.011$ & $0.28 \pm 0.011$ & $0.27 \pm 0.010$ & ns \\
\hline $17: 1 c 9$ & $0.28 \pm 0.007$ & $0.27 \pm 0.011$ & $0.28 \pm 0.006$ & $0.27 \pm 0.008$ & $0.27 \pm 0.008$ & $0.29 \pm 0.004$ & $0.28 \pm 0.008$ & $0.29 \pm 0.008$ & $0.28 \pm 0.008$ & $0.29 \pm 0.008$ & ns \\
\hline DMA-18:0 & $0.09 \pm 0.012$ & $0.09 \pm 0.021$ & $0.08 \pm 0.012$ & $0.08 \pm 0.015$ & $0.06 \pm 0.013$ & $0.08 \pm 0.007$ & $0.07 \pm 0.014$ & $0.11 \pm 0.015$ & $0.07 \pm 0.015$ & $0.07 \pm 0.015$ & ns \\
\hline $18: 0$ & $12.8 \pm 0.289$ & $13.4 \pm 0.485$ & $13.0 \pm 0.280$ & $12.6 \pm 0.359$ & $12.5 \pm 0.308$ & $12.9 \pm 0.162$ & $12.6 \pm 0.322$ & $12.8 \pm 0.352$ & $12.7 \pm 0.357$ & $12.6 \pm 0.344$ & ns \\
\hline $18: 1 \mathrm{c} 9$ & $45.5 \pm 0.468$ & $44.5 \pm 0.785$ & $44.8 \pm 0.453$ & $43.7 \pm 0.582$ & $45.7 \pm 0.498$ & $44.8 \pm 0.262$ & $44.6 \pm 0.521$ & $44.7 \pm 0.569$ & $44.1 \pm 0.578$ & $45.2 \pm 0.557$ & ns \\
\hline 18:1c11 & $0.11 \pm 0.008$ & $0.10 \pm 0.012$ & $0.10 \pm 0.007$ & $0.09 \pm 0.009$ & $0.10 \pm 0.008$ & $0.09 \pm 0.004$ & $0.09 \pm 0.008$ & $0.10 \pm 0.009$ & $0.10 \pm 0.009$ & $0.10 \pm 0.007$ & ns \\
\hline $18: 2 n-6$ & $6.99 \pm 0.282$ & $6.47 \pm 0.474$ & $7.43 \pm 0.273$ & $6.65 \pm 0.300$ & $6.64 \pm 0.300$ & $6.72 \pm 0.158$ & $6.40 \pm 0.314$ & $6.78 \pm 0.343$ & $6.77 \pm 0.349$ & $7.03 \pm 0.336$ & ns \\
\hline $18: 3 n-6$ & $0.09 \pm 0.006$ & $0.11 \pm 0.010$ & $0.11 \pm 0.006$ & $0.11 \pm 0.007$ & $0.11 \pm 0.006$ & $0.11 \pm 0.003$ & $0.11 \pm 0.007$ & $0.11 \pm 0.007$ & $0.11 \pm 0.007$ & $0.11 \pm 0.007$ & ns \\
\hline $18: 3 n-3$ & $0.37 \pm 0.014$ & $0.34 \pm 0.024$ & $0.40 \pm 0.022$ & $0.35 \pm 0.009$ & $0.36 \pm 0.013$ & $0.36 \pm 0.004$ & $0.34 \pm 0.006$ & $0.34 \pm 0.006$ & $0.36 \pm 0.018$ & $0.38 \pm 0.018$ & ns \\
\hline $20: 0$ & $0.22 \pm 0.006$ & $0.23 \pm 0.010$ & $0.24 \pm 0.006$ & $0.22 \pm 0.007$ & $0.22 \pm 0.006$ & $0.22 \pm 0.003$ & $0.22 \pm 0.006$ & $0.22 \pm 0.007$ & $0.21 \pm 0.007$ & $0.22 \pm 0.007$ & ns \\
\hline 20:1c11 & $1.12 \pm 0.023$ & $1.14 \pm 0.022$ & $1.14 \pm 0.047$ & $1.11 \pm 0.028$ & $1.18 \pm 0.024$ & $1.14 \pm 0.013$ & $1.15 \pm 0.025$ & $1.17 \pm 0.028$ & $1.13 \pm 0.027$ & $1.15 \pm 0.027$ & ns \\
\hline $20: 2 n-6$ & $0.34 \pm 0.016$ & $0.39 \pm 0.025$ & $0.39 \pm 0.036$ & $0.34 \pm 0.020$ & $0.35 \pm 0.017$ & $0.34 \pm 0.009$ & $0.34 \pm 0.018$ & $0.34 \pm 0.019$ & $0.34 \pm 0.019$ & $0.36 \pm 0.019$ & ns \\
\hline $20: 3 n-6$ & $0.04 \pm 0.004$ & $0.03 \pm 0.007$ & $0.03 \pm 0.004$ & $0.03 \pm 0.005$ & $0.03 \pm 0.005$ & $0.03 \pm 0.002$ & $0.04 \pm 0.005$ & $0.03 \pm 0.005$ & $0.03 \pm 0.005$ & $0.03 \pm 0.005$ & ns \\
\hline $21: 0$ & $0.07 \pm 0.018$ & $0.07 \pm 0.007$ & $0.08 \pm 0.001$ & $0.07 \pm 0.009$ & $0.07 \pm 0.003$ & $0.08 \pm 0.001$ & $0.07 \pm 0.003$ & $0.08 \pm 0.004$ & $0.07 \pm 0.007$ & $0.08 \pm 0.002$ & ns \\
\hline $20: 4 n-6$ & $0.33 \pm 0.020$ & $0.29 \pm 0.033$ & $0.32 \pm 0.019$ & $0.34 \pm 0.024$ & $0.34 \pm 0.021$ & $0.34 \pm 0.011$ & $0.31 \pm 0.022$ & $0.37 \pm 0.024$ & $0.30 \pm 0.023$ & $0.32 \pm 0.023$ & ns \\
\hline $20: 3 n-3$ & $0.09 \pm 0.008^{\mathrm{ab}}$ & $0.08 \pm 0.013^{\mathrm{ab}}$ & $0.09 \pm 0.007^{\mathrm{ab}}$ & $0.07 \pm 0.009^{\mathrm{ab}}$ & $0.08 \pm 0.004^{\mathrm{ab}}$ & $0.08 \pm 0.004^{\mathrm{b}}$ & $0.10 \pm 0.008^{\mathrm{ab}}$ & $0.12 \pm 0.009^{\mathrm{b}}$ & $0.12 \pm 0.009^{\mathrm{ab}}$ & $0.11 \pm 0.009^{\mathrm{ab}}$ & * \\
\hline $22: 0$ & $0.03 \pm 0.004$ & $0.02 \pm 0.006$ & $0.02 \pm 0.004$ & $0.02 \pm 0.005$ & $0.02 \pm 0.004$ & $0.02 \pm 0.002$ & $0.02 \pm 0.004$ & $0.03 \pm 0.005$ & $0.02 \pm 0.005$ & $0.02 \pm 0.004$ & ns \\
\hline $20: 5 n-3$ & $0.02 \pm 0.003$ & $0.02 \pm 0.005$ & $0.02 \pm 0.003$ & $0.01 \pm 0.004$ & $0.02 \pm 0.003$ & $0.02 \pm 0.002$ & $0.02 \pm 0.003$ & $0.03 \pm 0.003$ & $0.02 \pm 0.003$ & $0.02 \pm 0.003$ & ns \\
\hline $22: 1 n-9$ & $0.02 \pm 0.006^{\mathrm{b}}$ & $0.06 \pm 0.010^{\mathrm{ab}}$ & $0.05 \pm 0.006^{\mathrm{ab}}$ & $0.04 \pm 0.008^{\mathrm{ab}}$ & $0.05 \pm 0.006^{\mathrm{ab}}$ & $0.05 \pm 0.003^{\mathrm{a}}$ & $0.05 \pm 0.007^{\mathrm{ab}}$ & $0.06 \pm 0.007^{\mathrm{b}}$ & $0.06 \pm 0.007^{\mathrm{ab}}$ & $0.05 \pm 0.007^{\mathrm{ab}}$ & $*$ \\
\hline $22: 5 n-3$ & $0.04 \pm 0.013^{\mathrm{b}}$ & $0.06 \pm 0.021^{\mathrm{ab}}$ & $0.10 \pm 0.012^{\mathrm{ab}}$ & $0.06 \pm 0.016^{\mathrm{ab}}$ & $0.09 \pm 0.013^{\mathrm{ab}}$ & $0.06 \pm 0.007^{\mathrm{b}}$ & $0.13 \pm 0.014^{\mathrm{a}}$ & $0.05 \pm 0.015^{\mathrm{b}}$ & $0.04 \pm 0.015^{\mathrm{b}}$ & $0.08 \pm 0.015^{\mathrm{ab}}$ & * \\
\hline $22: 6 n-3$ & $0.01 \pm 0.007^{\mathrm{b}}$ & $0.04 \pm 0.012^{\mathrm{ab}}$ & $0.03 \pm 0.007^{\mathrm{ab}}$ & $0.02 \pm 0.009^{\mathrm{ab}}$ & $0.02 \pm 0.008^{\mathrm{ab}}$ & $0.05 \pm 0.004^{\mathrm{a}}$ & $0.05 \pm 0.008^{\mathrm{ab}}$ & $0.06 \pm 0.009^{\mathrm{a}}$ & $0.06 \pm 0.009^{\mathrm{a}}$ & $0.04 \pm 0.009^{\mathrm{ab}}$ & ** \\
\hline Others & $3.05 \pm 0.920$ & $3.88 \pm 1.540$ & $3.01 \pm 0.889$ & $6.38 \pm 1.143$ & $4.20 \pm 0.974$ & $4.14 \pm 0.513$ & $5.60 \pm 1.018$ & $3.85 \pm 1.118$ & $4.97 \pm 1.115$ & $4.02 \pm 1.093$ & ns \\
\hline \multicolumn{12}{|c|}{ Fatty acid partial sums } \\
\hline SFA & $38.7 \pm 0.608$ & $39.6 \pm 1.018$ & $39.0 \pm 0.588$ & $37.8 \pm 0.755$ & $37.7 \pm 0.644$ & $38.6 \pm 0.339$ & $37.7 \pm 0.673$ & $38.8 \pm 0.739$ & $38.4 \pm 0.737$ & $38.0 \pm 0.723$ & ns \\
\hline MUFA & $49.7 \pm 0.513$ & $48.6 \pm 0.858$ & $48.9 \pm 0.495$ & $47.7 \pm 0.637$ & $49.9 \pm 0.543$ & $48.9 \pm 0.286$ & $48.7 \pm 0.568$ & $48.8 \pm 0.623$ & $48.3 \pm 0.621$ & $49.3 \pm 0.609$ & ns \\
\hline PUFA & $8.34 \pm 0.327$ & $7.76 \pm 0.548$ & $8.91 \pm 0.316$ & $8.00 \pm 0.407$ & $8.05 \pm 0.347$ & $8.12 \pm 0.183$ & $7.85 \pm 0.362$ & $8.26 \pm 0.398$ & $8.14 \pm 0.397$ & $8.48 \pm 0.389$ & ns \\
\hline$n-6$ PUFA & $7.81 \pm 0.306$ & $7.23 \pm 0.512$ & $8.29 \pm 0.296$ & $7.47 \pm 0.380$ & $7.47 \pm 0.324$ & $7.54 \pm 0.171$ & $7.20 \pm 0.339$ & $7.64 \pm 0.372$ & $7.54 \pm 0.371$ & $7.85 \pm 0.364$ & ns \\
\hline$n-3$ PUFA & $0.53 \pm 0.025$ & $0.53 \pm 0.042$ & $0.62 \pm 0.039$ & $0.52 \pm 0.031$ & $0.58 \pm 0.027$ & $0.58 \pm 0.014$ & $0.65 \pm 0.028$ & $0.62 \pm 0.031$ & $0.60 \pm 0.030$ & $0.62 \pm 0.030$ & ns \\
\hline DMA & $0.21 \pm 0.019$ & $0.18 \pm 0.032$ & $0.16 \pm 0.018$ & $0.17 \pm 0.023$ & $0.14 \pm 0.020$ & $0.17 \pm 0.011$ & $0.16 \pm 0.021$ & $0.24 \pm 0.023$ & $0.18 \pm 0.023$ & $0.16 \pm 0.022$ & ns \\
\hline \multicolumn{12}{|c|}{ Fatty acid ratios } \\
\hline PUFA/SFA & $0.22 \pm 0.010$ & & $0.23 \pm 0.010$ & $0.21 \pm 0.012$ & $0.21 \pm 0.010$ & $0.21 \pm 0.005$ & $0.21 \pm 0.011$ & $0.21 \pm 0.012$ & $0.21 \pm 0.012$ & $0.22 \pm 0.012$ & ns \\
\hline$n-6 / n-3$ & $14.6 \pm 0.336^{\mathrm{a}}$ & $13.6 \pm 0.562^{\mathrm{ab}}$ & $13.3 \pm 0.324^{\mathrm{ab}}$ & $14.2 \pm 0.417^{\mathrm{ab}}$ & $12.8 \pm 0.355^{\mathrm{ab}}$ & $13.1 \pm 0.187^{b}$ & $11.0 \pm 0.371^{\mathrm{c}}$ & $12.3 \pm 0.408^{\mathrm{bc}}$ & $12.6 \pm 0.406^{\mathrm{bc}}$ & $12.6 \pm 0.399^{\mathrm{bc}}$ & $* * *$ \\
\hline
\end{tabular}

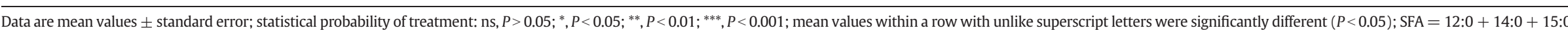

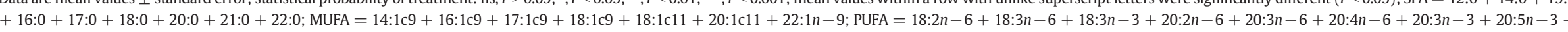

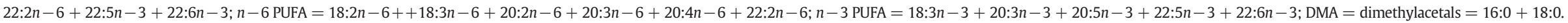




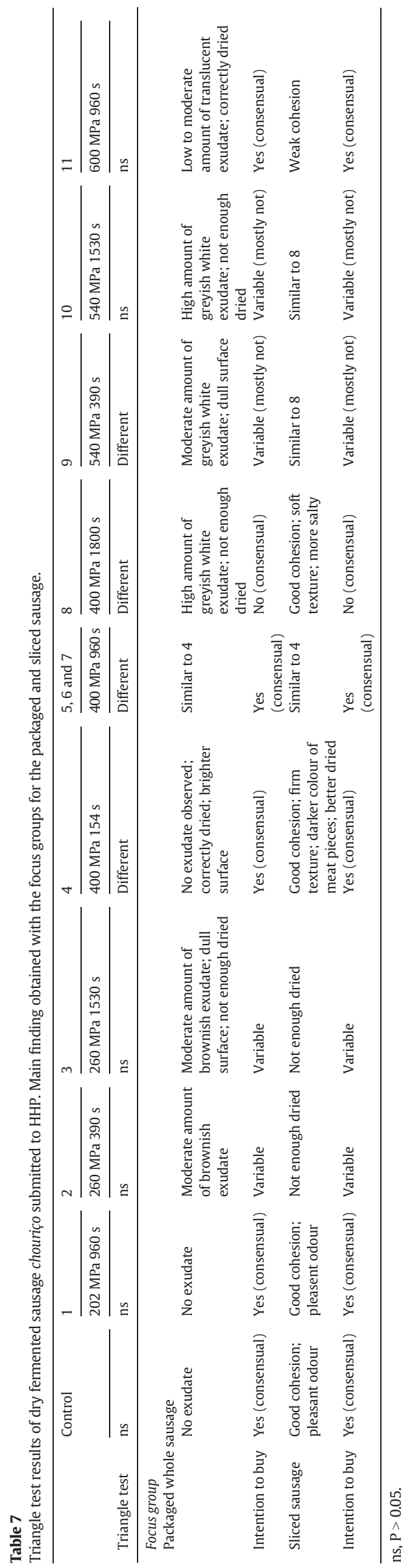

increases the water amount in the product (Chen et al., 2010; Sikes, Aarti, Tobin, \& Tume, 2009; Souza et al., 2011), that might be the reason of the inversion of the trend observed in the treatment $600 \mathrm{MPa}-960 \mathrm{~s}$ that had only a low to moderate amounts of exudates that seem to be qualitatively different from those of the DFS treated under lower pressures. In dry cured meat products Marcos, Aymerich, Guardia, and Garriga (2007) did not find any difference of using a HPP treatment in chorizo and fuet in the most part of the texture and colour parameters analysed, suggesting that in their experiment the WHC was not affected by the $400 \mathrm{MPa}$ during $10 \mathrm{~min}$. In the present work, it was also with treatments of $400 \mathrm{MPa}$ for $154 \mathrm{~s}$ or $960 \mathrm{~s}$ that the exudates were not observed, but increasing the holding time, the consequences were negative, due to the occurrence of the greyish white exudates considered by the focus group participants in moderate to high amounts.

The brownish exudates in small to moderate amounts might be a combination of water loss; the red pepper paste and the smoke components in the casing resulting in the brownish exudates were observed. The exudate observed when stronger HPP treatments were used was possibly composed by water and soluble materials from the myofibrils (Nishiwaki, Ikeuchi, \& Suzuki, 1996), or from the sarcoplasmic proteins (Marcos \& Mullen, 2014) due to pressurisation resulting in the milky aspect of the exudate. Due to the amount of unsaturated FA (Table 6), with low melting point, it is possible that during the pressurisation some liquid fat has been squeezed into the exudate, contributing to its greyish white aspect.

When whole sausages were taken from the package, the aspect of the sausages was unanimously considered to improve. The aspect of the casings was considered not appellative in samples with higher treatments, due to its dull and not translucent as expected aspect.

Samples of DFS were sliced and presented monadically to participants to evaluate the characteristics of aspect, odour, taste, flavour and texture. As observed for the packaged chouriço, several descriptive terms were related to the formulation and manufacturing technology - amount of fat and red pepper paste; size of meat and fat pieces, smoke and ripened odour, sour and bitter taste. Other characteristics could be related to the HPP treatment, once they were variable among the samples with different treatments. These attributes include the cohesion of the meat and fat pieces, colour of the meat, the moisten aspect, the salty taste and the soft texture. The texture attributes were probably determined by the same mechanisms involved in the formation of exudates. In one experimental condition (400 MPa, $960 \mathrm{~s}$ ), the salty taste was invocated by several participants. Considering that all sausages were obtained from the same production batch, that difference might be a result of the modifications induced by the treatment, as previously observed by Picouet, Sala, Garcia-Gil, Nolis, and Colleo (2012), the application of HPP could increase the saltiness perception of the meat products due to the effect of concentration by the water loss, and to the liberation of a proportion of sodium that is bonded to proteins.

When results from the triangle test and from the focus groups are compared, it is possible to observe that the differences detected by the triangle test in HPP treated DFS were not necessarily for worst. Those pressurised at $400 \mathrm{MPa}$ during $154 \mathrm{~s}$ or $960 \mathrm{~s}$ have less defects and were considered appellative by the groups.

\section{Conclusions}

High pressure ( $>400 \mathrm{MPa}$ and longer time than $154 \mathrm{~s}$ ) produced a reduction in fungi, aerobic count and on Gram negative bacteria, such as Enterobacteriaceae and Pseudomonas, without negative effect on Gram positive fermentative microbiota ( $\mathrm{LAB}$ ). This seems to be beneficial on dry fermented sausages since it will be possible to have a reduction of the spoilage microorganisms while the technological fermentative bacteria will survive in the product and have the opportunity to contribute for the safety and sensory maturation of the DFS. Total fatty acids and lipid stability were not affected by HPP. Only a small effect on FA composition was observed. Moreover, the nutritional value of the lipid fraction was 
only affected by the ratio of $n-6 / n-3$ FA, and their stability. The treatments at $400 \mathrm{MPa}$ for $154 \mathrm{~s}$ or $960 \mathrm{~s}$ resulted in DFS that were detected as different from the control by sensory analysis but they were not necessarily worst. The modifications induced by these HPP treatments seem to improve some sensory attributes of the DFS, namely the bright aspect of the whole sausage, the cohesion and firmness and the correctly dried aspect of the slices.

Based on the results, HPP can be employed; particularly 400 MPa no more than $960 \mathrm{~s}$, as a useful tool to improve value added meat products with increased microbial quality and sensorial quality desired by consumers.

\section{Acknowledgments}

This work was supported by national funds through FCT - Fundação para a Ciência e a Tecnologia under the Project PTDC/AGR-ALI/119075/ 2010. The authors thank Paladares Alentejanos Lda. and Q-Staff, Consultoria, Lda.

\section{References}

Bajovic, B., Bolumar, T., \& Heinz, V. (2012). Quality considerations with high pressure processing of fresh and value added meat products: Review. Meat Science, 92, 280-289.

Beltran, E., Pla, R., Yuste, J., \& Mor-Mur, M. (2004). Use of antioxidants to minimize rancidity in pressurized and cooked chicken slurries. Meat Science, 66, 719-725.

Boselli, E., Velazco, V., Caboni, M. F., \& Lercker, G. (2001). Pressurized liquid extraction of lipids for the determination of oxysterols in egg-containing food. Journal of Chromatography A, 917, 239-244.

Chen, C., Wang, R., Sun, G., Fang, H., Ma, D., \& Yi, S. (2010). Effects of high pressure level and holding time on properties of duck muscle gels containing $1 \%$ curdlan. Innovative Food Science \& Emerging Technologies, 11, 538-542.

Chung, H. S., Hong, H. -D., Kim, K., Cho, C. -W., \& Moskowitz, H. R. (2011). Consumer attitudes and expectations of ginseng food products assessed by focus groups and conjoint analysis. Journal of Sensory Studies, 26, 346-357.

Clariana, M., Guerrero, L., Sárraga, C., Díaz, I., Valero, Á., \& García-Regueiro, J. A. (2011). Influence of high pressure application on the nutritional, sensory and microbiological characteristics of sliced skin vacuum packed dry-cured ham. Effects along the storage period. Innovative Food Science \& Emerging Technologies, 12, 456-465.

Department of Health (1994). Nutritional aspects of cardiovascular disease: HMSO (England). Report on Health and Social Subjects, 46 (pp. 37-46).

Fraqueza, M. J., \& Barreto, A. S. (2015). HACCP: hazard analysis and critical control points. In F. Toldra, Y. H. Hui, I. Astiasaran, J. Sebranek, \& R. Talon (Eds.), Handbook of Fermented Meat and Poultry (pp. 469-486) (2nd Edition ). UK: Wiley-395 Blackwell.

Garriga, M., Grèbol, N., Aymerich, M. T., Monfort, J. M., \& Hugas, M. (2004). Microbial inactivation after high-pressure processing at $600 \mathrm{MPa}$ in commercial meat products over its shelf life. Innovative Food Science E Emerging Technologies, 5, 451-457.

Giovanni, M. (1987). Response surface methodology and product optimization. Food Technology, 37, 41-45.

Grau, A., Guardiola, F., Boatella, J., \& Codonyl, R. (2000). Measurement of 2-thiobarbituric acid values in dark chicken meat through derivative spectrophotometry: influence of various parameters. Journal of Agricultural and Food Chemistry, 48, 1155-1159.

Guillén, M. D., \& Ruiz, A. (2004). Study of the oxidative stability of salted and unsalted salmon fillets by ${ }^{1} \mathrm{H}$ nuclear magnetic resonance. Food Chemistry, 86, 297-304.

Hazel, J. R., \& Williams, E. E. (1990). The role of alterations in membrane lipid composition in enabling physiological adaptation of organisms to their physical environment. Progress in Lipid Research, 29, 167-227.

Hoover, D. G., Dishart, K. J., \& Hermes, M. A. (1989). Antagonistic effect of Pediococcus spp. against Listeria monocytogenes. Food Biotechnology, 3, 183-196.

Ikeuchi, Y. (2011). Recent advances in the application of high pressure technology to processed meat products. In J. P. Kerry, \& K.J.F. (Eds.), Processed meats - Improving safety, nutrition and quality (pp. 590-609). Cambridge: Woodhead Publishing.

ISO 16649-2 (2001). Microbiology of food and animal feeding stuffs - Horizontal method for the enumeration of beta-glucuronidase-positive Escherichia coli - Part 2. Colonycount technique at 44 degrees C using 5-bromo-4-chloro-3-indolyl beta-D-glucuronide.

ISO 4120 (2004). Sensory analysis - Methodology - Triangle test.

Leistner, L., Rodel, W., \& Krispien, K. (1981). Microbiology of meat and meat products in high and intermediate moisture ranges. In L. B. Rockland, \& G. F. Stewart (Eds.), Water activity. Influences on food quality (pp. 855-916). New York: Academic Press.

Lerasle, M., Federighi, M., Simonin, H., Anthoine, V., Rezé, S., Chéret, R., \& Guillou, S. (2014). Combined use of modified atmosphere packaging and high pressure to extend the shelf-life of raw poultry sausage. Innovative Food Science and Emerging Technologies, 23, 54-60.

MacFarlane, J. J., McKenzie, I. J., \& Turner, R. H. (1980). Pressure induced pH and length changes in meat. Meat Science, 7, 169-181.

Marcos, B., \& Mullen, A. M. (2014). High pressure induced changes in beef muscle proteome: correlation with quality parameters. Meat Science, 97, 11-20.

Marcos, B., Aymerich, T., Guardia, M. D., \& Garriga, M. (2007). Assessment of high hydrostatic pressure and starter culture on the quality properties of low-acid fermented sausages. Meat Science, 76, 46-53.

Marqués, J., Vila-Real, H., Alfaia, A. J., \& Ribeiro, M. H. L. (2007). Modelling of the high pressure-temperature effects on naringin hydrolysis based on response surface methodology. Food Chemistry, 105, 504-510.

McArdle, R., Marcos, B., Kerry, J. P., \& Mullen, A. M. (2010). Monitoring the effects of high pressure processing and temperature on selected beef quality attributes. Meat Science, 86, 629-634.

Morrissey, P. A., Sheehy, P. J. A., Galvin, K., Kerry, J. P., \& Buckley, D. J. (1998). Lipid stability in meat and meat products. Meat Science, 49, S73-S86.

Nishiwaki, T., Ikeuchi, Y., \& Suzuki, A. (1996). Effects of high pressure treatment on Mgenhanced ATPase activity of rabbit myofibrils. Meat Science, 43, 145-155.

O'Fallon, J. V., Busboom, J. R., Nelson, M. L., \& Gaskins, C. T. (2007). A direct method for fatty acid methyl ester synthesis: application to wet meat tissues, oils, and feedstuffs. Journal of Animal Science, 85, 1511-1521.

Rendueles, E., Omer, M. K., Alvseike, O., Alonso-Calleja, C., Capita, R., \& Prieto, M. (2011). Microbiological food safety assessment of high hydrostatic pressure processing: A review. LWT - Food Science and Technology, 44, 1251-1260.

Ordoñez, J. A., Hierro, E., Bruna, J. M., \& de la Hoz, L. (1999). Changes in the components of dry-fermented sausage during ripening. Critical Reviews in Food Science and Nutrition, 39, 329-367.

Orlien, V., Hansen, E., \& Skibsted, L. H. (2000). Lipid oxidation in high-pressure processed chicken breast muscle during chill storage: Critical working pressure in relation to oxidation mechanism. European Food Research and Technology, 211, 99-104.

Picouet, P. A., Sala, X., Garcia-Gil, N., Nolis, P., \& Colleo, M. (2012). High pressure processing of dry-cured ham: Ultrastructural and molecular changes affecting sodium and water dynamics. Innovative Food Science E Emerging Technologies, 16, 335-340.

Rastogi, N. K., Raghavarao, K. S., Balasubramaniam, V. M., Niranjan, K., \& Knorr, D. (2007) Opportunities and challenges in high pressure processing of foods. Critical Reviews in Food Science and Nutrition, 47, 69-112.

Ribeiro, M. H. L., Silveira, D., Ebert, C., \& Ferreira-Dias, S. (2003). Response surface modelling of the consumption of bitter compounds from orange juice by Acinetobacter calcoaceticus. Journal of Molecular Catalysis B, 21, 81-88.

Rodríguez-Calleja, J. M., Cruz-Romero, M. C., Sullivan, M. G. O., García-López, M. L., \& Kerry, J. P. (2012). High-pressure-based hurdle strategy to extend the shelf-life of fresh chicken breast fillets. Food Control, 25, 516-524.

Shigehisa, T., Ohmori, T., Saito, A., Taji, S., \& Hayashi, R. (1991). Effects of high hydrostatic pressure on characteristics of pork slurries and inactivation of microorganisms associated with meat and meat products. International Journal of Food Microbiology, 12, 207-215.

Shimada, S., Andou, M., Naito, N., Yamada, N., Osumi, M., \& Hayashi, R. (1993). Effects of hydrostatic pressure on the ultrastructure and leakage of internal substances in the yeast Saccharomyces cerevisiae. Applied Microbiology and Biotechnology, 40, 123-131.

Sikes, A. L., Aarti, B., Tobin, A. B., \& Tume, R. K. (2009). Use of high pressure to reduce cook loss and improve texture of low-salt beef sausage batters. Innovative Food Science $\mathcal{E}$ Emerging Technologies, 10, 405-412.

Simopoulos, A. P. (2008). The omega-6/omega-3 fatty acid ratio, genetic variation, and cardiovascular disease. Asia Pacific Journal of Clinical Nutrition, 17, 131-134.

Simpson, R. K., \& Gilmour, A. (1997). The effect of high hydrostatic pressure on Listeria monocytogenes in phosphate-buffered saline and model food systems. Journal of Applied Microbiology, 83, 181-188.

Souza, C. M., Boler, D. D., Clark, D. L., Kutzler, L. W., Holmer, S. F., et al. (2011). The effects of high pressure processing on pork quality, palatability, and further processed products. Meat Science, 87, 419-427.

Sun, X. D., \& Holley, R. A. (2010). High hydrostatic pressure effects on the texture of meat and meat products. Journal of Food Science, 75, 17-23.

Talon, R., Lebert, I., Lebert, A., Leroy, S., Garriga, M., et al. (2007). Traditional dry fermented sausages produced in small-scale processing units in Mediterranean countries and Slovakia. 1. Microbial ecosystems of processing environments. Meat Science, 77 570-579.

Tuboly, E., Lebovics, V. K., Gaál, Ö., Mészáros, L., \& Farkas, J. (2003). Microbiological and lipid oxidation studies on mechanically deboned Turkey meat treated by high hydrostatic pressure. Journal of Food Engineering, 56, 241-244.

Vuataz, L. (1986). Statistical procedures in food research. London: Elsevier.

Wood, J. D., Enser, M., Fisher, A. V., Nute, G. R., Sheard, P. R., et al. (2008). Fat deposition, fatty acid composition and meat quality: A review. Meat Science, 78, 343-358.

Zhang, H., \& Mittal, G. S. (2008). Effects of high-pressure processing (HPP) on bacterial spores: An overview. Food Reviews International, 24, 330-351. 